\title{
Identification of Essential Histidines in Cyclodextrin Glycosyltransferase Isoform 1 from Paenibacillus sp. A11
}

\author{
Jarunee Kaulpiboon and Piamsook Pongsawasdi* \\ Department of Biochemistry, Faculty of Science, Chulalongkorn University, Bangkok 10330, Thailand
}

Received 30 January 2003, Accepted 4 March 2003

The isoform 1 of cyclodextrin glycosyltransferase (CGTase, EC 2.4.1.19) from Paenibacillus sp. A11 was purified by a preparative gel electrophoresis. The importance of histidine, tryptophan, tyrosine, and carboxylic amino acids for isoform 1 activity is suggested by the modification of the isoform 1 with various groupspecific reagents. Activity loss, when incubated with diethylpyrocarbonate (DEP), a histidine modifying reagent, could be protected by adding $25 \mathrm{mM}$ methyl- $\beta$ cyclodextrin substrate prior to the modification. Inactivation kinetics of isoform 1 with DEP resulted in second-order rate constants $\left(k_{\text {inactivation }}\right)$ of $29.5 \mathrm{M}^{-1} \mathrm{~s}^{-1}$. The specificity of the DEP-modified reaction for the histidine residue was shown by the correlation between the loss of isoform activity and the increase in the absorbance at 246 nm of $N$-carbethoxyhistidine. The number of histidines that were modified by DEP in the absence and presence of a protective substrate was estimated from the increase in the absorbance using a specific extinction coefficient of $\mathrm{N}$ carbethoxyhistidine of $3,200 \mathrm{M}^{-1} \mathrm{~cm}^{-1}$. It was discovered that methyl- $\beta-C D$ protected per mole of isoform 1 , two histidine residues from the modification by DEP. To localize essential histidines, the native, the DEP-modified, and the protected forms of isoform 1 were digested by trypsin. The resulting peptides were separated by HPLC. The peptides of interest were those with $R_{t} 11.34$ and $40.93 \mathrm{~min}$. The molecular masses of the two peptides were 5,732 and 2,540 daltons, respectively. When the data from the peptide analysis were checked with the sequence of CGTase, then His-140 and His-327 were identified as essential histidines in the active site of isoform 1.

Keywords: Cyclodextrin glycosyltransferase, Paenibacillus, Chemical modification, Essential histidine residue

*To whom correspondence should be addressed.

Tel: 662-218-5419; Fax: 662-218-5418

E-mail: Piamsook.P@chula.ac.th

\section{Introduction}

For several years, cyclodextrins (CDs) have been known for their applications in industries, particularly food, cosmetics, and pharmaceutical industries (Bender, 1986). Alpha, beta, and gamma-CDs are three main native forms that have been reported. They are cyclic oligosaccharides of 6,7 , and 8 glucose units, respectively. Several bacteria species are capable of producing CDs from starch by using their extracellular enzymes known as cyclodextrin glycosyltransferase (CGTase). The enzyme CGTase is classified as a member of the $\alpha$ amylase family due to similar structural domains for starch hydrolysis. However, CGTase has additional domains that allow it to form cyclic oligosaccharide products (Bart et al., 2000). The enzyme is produced by various microorganisms, for example Klebsiella pneumoniae M5a1 (Bender,1986), Micrococcus sp. (Yagi et al., 1986), and mainly Bacillus sp. (Kitahata et al., 1974; Kobayashi et al., 1978; Kitahata and Okada, 1982a, b). CGTases from different sources were reported to have different characteristics, such as working $\mathrm{pH}$, temperature, and molecular weight. Each CGTase enzyme yields a different major product. For example, Klebsiella pneumoniae M5a1 CGTase mainly produces $\alpha-\mathrm{CD}$, while CGTase of alkalophilic Bacillus sp. 38-2 gives $\beta-C D$ as its main product. A few CGTases reportedly contained multiple forms. They are referred to as isozymes (Nakamura and Horikoshi, 1976), isoforms (Kaskangam, 1998), or subforms (Mattsson et al., 1990). The existence of multiple forms of the enzyme is not yet completely understood.

CGTase from Paenibacillus sp. A11 contained 4 isoforms, discovered by the work of our group (Kaskangam, 1998). They were separated by preparative gel electrophoresis. Each isoform had the same molecular weight of $72 \mathrm{kDa}$, but with different $\mathrm{pI}$, product ratio, and carbohydrate content. Isoform 1 with the highest $\mathrm{pI}$ value of 4.73 was the major form. The aim of the present work is to investigate the active site of CGTase isoform 1. This study will lead to more insights into understanding the multiple forms of the enzyme as well as the ability to compare it with other CGTases. 


\section{Materials and Methods}

Chemicals and bacterial strain All of the chemicals that were used were purchased from Sigma Chemical Co. (St. Louis, USA). Paenibacillus sp. A11 isolated from South-East Asian soil, was screened for CGTase activity by Pongsawasdi and Yagisawa (1987).

Assay of CGTase The dextrinizing activity of CGTase was assayed by measuring the reduction in the intensity of the blue color of the starch-iodine complex (Fuwa, 1954). In a typical experiment, the enzyme sample $(5-100 \mu \mathrm{l})$ was incubated with $0.3 \mathrm{ml}$ of the starch substrate $(0.2 \% \mathrm{w} / \mathrm{v}$ soluble starch (potato) in a $0.2 \mathrm{M}$ phosphate buffer, $\mathrm{pH} 6.0$ ) at $40^{\circ} \mathrm{C}$ for $10 \mathrm{~min}$. The reaction was stopped with $4 \mathrm{ml}$ of $0.2 \mathrm{~N} \mathrm{HCl}$. Then $0.5 \mathrm{ml}$ of the iodine reagent $\left(0.02 \% \mathrm{I}_{2}\right.$ in $\left.0.2 \% \mathrm{KI}\right)$ was added. The mixture was adjusted to a final volume of $10 \mathrm{ml}$ with distilled water, and its absorbance at $600 \mathrm{~nm}$ was measured. For the control, the $\mathrm{HCl}$ was added before the enzyme sample. The protein concentration was determined by the Coomassie blue method (Bradford, 1976), using bovine serum albumin as the standard.

Purification of CGTase isoform 1 CGTase was partially purified from the culture broth of Paenibacillus sp. A11 by starch adsorption (Kato and Horikoshi, 1984), and then concentrated by ultrafiltration before loading on a preparative gel electrophoresis Model 491 Prep cell (Bio-Rad, Hercules, USA). The electrophoresis was run from cathode towards anode at a constant power of $12 \mathrm{~W}$ (Kaskangam, 1998). The proteins were eluted from the gel with an electrode buffer at a flow rate of $1 \mathrm{ml} / \mathrm{min}$. Fractions of $2.5 \mathrm{ml}$ were collected and measured for $\mathrm{A}_{280}$ and CGTase activity. Every 5 fractions were run on slab gels and stained for dextrinizing activity. Then the fractions that gave the electrophoretic band with the same mobility were pooled. Isoform 1 was the last pool, due to having the least negative charge when compared to other isoforms.

Chemical modification with group-specific reagents To investigate the active site residue of this enzyme, various groupspecific reagents were tested for their ability to inactivate the CGTase isoform 1 activity. CGTase isoform 1 in a $50 \mathrm{mM}$ acetate buffer, $\mathrm{pH}$ 6.0, was incubated with reagents (Means and Feeney, 1971; Lee and $\mathrm{Cho}, 2002$ ) at $40^{\circ} \mathrm{C}$ for $30 \mathrm{~min}$. The final concentrations of the enzyme and reagents were $25 \mu \mathrm{g} / \mathrm{ml}$ and $1 \mathrm{mM}$, respectively. The total volume of the reaction mixture was $60 \mu \mathrm{l}$. After incubation, the samples $(10 \mu \mathrm{l})$ were removed from these reaction mixtures and the residual activities were measured. For an investigation on the essential histidines, the kinetics of inactivation were studied under various DEP concentrations, a specific reagent for histidine modification.

Protection of inactivation by substrate The experiment was performed by incubating a suitable DEP concentration with the CGTase isoform 1 in the presence or absence of methyl- $\beta-C D$ as a protective substance. The CGTase isoform 1 in a $50 \mathrm{mM}$ acetate buffer, $\mathrm{pH} 6.0$, was preincubated with $25 \mathrm{mM}$ of methyl- $\beta-\mathrm{CD}$ at $40^{\circ} \mathrm{C}$ for $5 \mathrm{~min}$ prior to the addition of a suitable DEP concentration (Tongsima, 1998). The final concentration of isoform 1 was $25 \mu \mathrm{g} /$ $\mathrm{ml}$. The total volume of the reaction mixture was $60 \mu \mathrm{l}$. After incubation with DEP for $30 \mathrm{~min}$, the residual CGTase isoform 1 activity was determined.

Determination of the number of essential histidine residues of CGTase isoform 1 To measure the number of DEP-modified histidine residues of the CGTase isoform 1 in the presence and absence of the protective substance, the differential increase in the absorbance at $246 \mathrm{~nm}$ between the two conditions was followed (Wakayama et al., 1996 ). The reaction was performed in a 1-cm pathlength quartz cuvette, consisting of $0.325 \mathrm{mM}$ DEP and $0.05 \mathrm{~g} / \mathrm{l} \mathrm{CGTase}$ isoform 1 in the presence or absence of $25 \mathrm{mM}$ methyl- $\beta-C D$. The protection time was $5 \mathrm{~min}$, while the modification time was $30 \mathrm{~min}$. The cuvette was put into the sample chamber of a spectrophotometer, and the temperature inside was set at $40^{\circ} \mathrm{C}$. The absorbance at $246 \mathrm{~nm}$ was then recorded.

The number ( $\mathrm{n}$ ) of modified histidine residues was calculated by using the following equation:

$$
\mathrm{n}=\frac{\mathrm{A}_{246} \times M_{\mathrm{r}}}{\varepsilon_{246} \times \mathrm{C}}
$$

where $M_{\mathrm{r}}$ is the molecular weight of the CGTase isoform 1 which is 72,000 (Kaskangam, 1998), $\varepsilon_{246}$ of $N$-carbethoxyhistidine (DEPmodified histidine) is $3,200 \mathrm{M}^{-1} \mathrm{~cm}^{-1}$ (Wakayama, 1996), and $\mathrm{C}$ is the CGTase isoform 1 concentration $(\mathrm{g} / \mathrm{l})$.

Digestion of isoform 1 and separation of peptides Three forms of isoform 1 (native, DEP-modified, and protected forms) were digested by trypsin at a ratio of $1: 80(\mathrm{w} / \mathrm{w})$ in a $0.2 \mathrm{M}$ Tris- $\mathrm{HCl}$ buffer, $\mathrm{pH} 8.0$, for $18 \mathrm{~h}$ at $37^{\circ} \mathrm{C}$ (Delforge et al., 1997). Then a desalting column was used to separate the peptides from the other reagents in the reaction mixture. The fractions that contained the peptides were pooled, lyophilized, and dissolved in $60 \mu \mathrm{l}$ of ultra pure water before filtration with a $0.22 \mu \mathrm{m}$ filter. The peptides were then separated by a reversed phase HPLC on a $\mathrm{C}_{18}$ column $(0.46 \times$ $25 \mathrm{~cm}$ ) that was previously equilibrated with solvent A. Solvent A was $0.1 \%(\mathrm{v} / \mathrm{v})$ trifluoroacetic acid in water. Elution was made by mixing solvents A and B. Solvent B was the mixture of $0.1 \%(\mathrm{v} / \mathrm{v})$ trifluoroacetic acid in water and acetronitrile at the ratio of $1: 3$. The elution of HPLC was carried out at a flow rate of $1 \mathrm{ml} / \mathrm{min}$. The detection of peptides was performed at 210 and $246 \mathrm{~nm}$. Injecting the ultra pure water alone, under the same chromatographic conditions, was also performed as a control. The eluted peptides were collected and either frozen at $-80^{\circ} \mathrm{C}$ or lyophilized for further analysis.

Mass analysis of peptides Peptides of interest were dissolved in a solution of acetronitrile: $0.02 \%$ formic acid in water $(50: 50)$, and their masses were determined by mass spectrometer. The sample from the HPLC column was introduced into the Mass Spectrometer: TOF ESI-MS system by the electrospray ionization method. The ions were detected by a time-of-flight mass analysis and the $\mathrm{m} / \mathrm{z}$ ratio was determined with the on-line analyzer. The molecular mass was calculated according to Siuzdak, 1996.

Amino acid sequence determination of peptides Prior to the amino acid sequencing, the interested peptide peaks from HPLC were concentrated using Speedvac. Amino acid residues were analyzed from the $\mathrm{N}$-terminus by Edman degradation reaction. The peptide samples were hydrolyzed with $6 \mathrm{M} \mathrm{HCl}$ that contained $1 \%$ 
Table 1. Effect of various group-specific reagents on the CGTase activity isoform 1

\begin{tabular}{lcc}
\hline \multicolumn{1}{c}{ Reagent $(1 \mathrm{mM})^{*}$} & Amino acid involved & Residual activity $(\%)$ \\
\hline None & - & 100 \\
$N$-ethylmaleimide (NEM) & Cysteine & 99.8 \\
Iodoacetamide (IAM) & Cysteine & 97.6 \\
Dithiothreitol (DTT) & Cysteine & 98.1 \\
2,4,6-Trinitrobenzenesulfonic acid (TNBS) & Lysine & 100 \\
Phenylmethylsulfonyl fluoride (PMSF) & Serine & 100 \\
1-Ethyl-3-(3-dimethylaminopropyl) carbodiimide (EDC) & Carboxylic amino acids & 67.1 \\
Diethylpyrocarbonate (DEP) & Histidine & 0 \\
$N$-bromosuccinimide (NBS) & Tryptophan & 0 \\
$N$-acetylimidazole (NAI) & Tyrosine & 69.9 \\
\hline
\end{tabular}

*Incubation with $25 \mu \mathrm{g} / \mathrm{ml}$ enzyme at $40^{\circ} \mathrm{C}$ and $\mathrm{pH} 6.0$ for $30 \mathrm{~min}$.

phenol $(\mathrm{v} / \mathrm{v})$ in evacuated tubes at $110^{\circ} \mathrm{C}$ for $1 \mathrm{~h}$ per each cycle in the Waters Pico-Tag Workstation after they were derivatized with phenylisothiocyanate (PITC). The hydrolyzed sample was then dried under a vacuum and resuspended in a $100 \mu$ Picotag $^{\mathrm{TM}}$ sample diluent. The amino acid mixtures obtained were analyzed on a Picotag ${ }^{\mathrm{TM}}$ column $(0.39 \times 30 \mathrm{~cm})$ of the Waters 510 HPLC.

\section{Results}

Chemical modification of CGTase isoform 1 When isoform 1 was incubated with various group-specific reagents, it was discovered that all of the activity was lost in the presence of $1 \mathrm{mM}$ DEP or NBS (Table 1). Partial activity loss was observed when incubated with EDC and NAI. This indicates the importance of histidine, tryptophan, carboxylic amino acids, and tyrosine on the enzyme activity. The ineffectiveness of NEM, IAM, DTT, TNBS, and PMSF suggests that cysteine, lysine, and serine were not at the enzyme active site.

From the chemical modification result, it appeared that histidine was a very important residue in the enzyme catalysis; therefore, we investigated its presence at the active site. Inactivation kinetics and substrate protection experiments were then carried out.

Inactivation kinetics of CGTase isoform 1 with DEP The incubation of the CGTase isoform 1 with varying DEP concentrations $(0-1.0 \mathrm{mM})$ at $\mathrm{pH} 6.0$ and $40^{\circ} \mathrm{C}$ resulted in a time-dependent loss of CGTase isoform 1 activity. When the CGTase isoform 1 was incubated with $1.0 \mathrm{mM}$ DEP for 5 min, the residual activity was $10 \%$. And at every DEP concentration, the activity loss was exponential with the incubation time. The pseudo first-order rate constants $\left(k_{\text {inactivation }}\right)$ of these inactivation kinetics were determined from the slope of the plot between the logarithm of relative residual activity (\%) versus time at different DEP concentrations (Fig. 1A). A straight line was obtained for the plot of $k_{\text {inactivation }}$ versus the DEP concentration, and the second-order rate constant
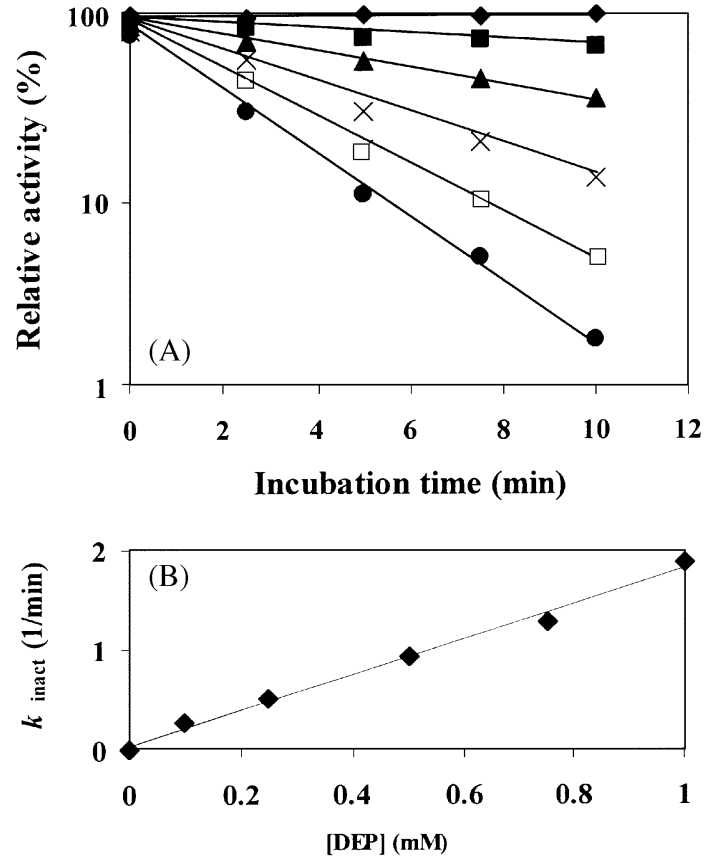

Fig. 1. Inactivation of CGTase isoform 1 with DEP. (A) CGTase isoform 1 was incubated with DEP at $0 \mathrm{mM}(\diamond), 0.10 \mathrm{mM}$ $(\boldsymbol{\square}), 0.25 \mathrm{mM}(\boldsymbol{\Delta}), 0.50 \mathrm{mM}(\times), 0.75 \mathrm{mM}(\square)$, and $1.0 \mathrm{mM}$ (O) for 0-10 min. The pseudo first-order rate constants of inactivation $k_{\text {inact }}$ were obtained from the slopes of straight lines. (B) Determination of the second-order rate constant of inactivation.

was $29.5 \mathrm{M}^{-1} \mathrm{~s}^{-1}$ (Fig. 1B). The double logarithmic plot of $k_{\text {inactivation }}$ versus the DEP concentration gave a slope value of 0.84 .

Protection of inactivation by substrate The suitable DEP concentration and inactivation time were $0.325 \mathrm{mM}$ and $5 \mathrm{~min}$ at $40^{\circ} \mathrm{C}$. At these conditions, approximately $50 \%$ activity was retained. To determine whether the histidine residue was involved at the active site of isoform 1, the modification DEP 
Table 2. Effect of substrate on the inactivation of CGTase isoform 1 by DEP

\begin{tabular}{lccc}
\hline \multicolumn{1}{c}{ Compound added } & \multicolumn{3}{c}{ Residual activity (\%) } \\
\cline { 2 - 4 } & I & II & 100 \\
\hline 1) None & 100 & 97.6 & 98.6 \\
2) $25 \mathrm{mM}$ Methyl- $\beta-C D$ & 99.5 & 77.5 & 74.2 \\
3) $25 \mathrm{mM}$ Methyl- $\beta-C D$, then $0.325 \mathrm{mM}$ DEP & 50.3 & 70.8 & 49.6 \\
4) $0.325 \mathrm{mM}$ DEP & 48.9 & \\
\hline
\end{tabular}

Numbers under I and II are duplicate values.

in the presence or absence of the substrate was compared. Table 2 shows that the modification by $0.325 \mathrm{mM}$ DEP led to a $50.4 \%$ loss of isoform 1 activity. When isoform 1 that was preincubated with the substrate was modified by DEP, the loss of isoform 1 activity was partially reduced. In the presence of methyl- $\beta-C D$, the activity loss was $26 \%$.

\section{Determination of the number of essential histidine} residues of CGTase isoform 1 The specificity of the DEPmodified reaction for the histidine residue was shown by the correlation between the loss of isoform 1 activity and the increase in absorbance at $246 \mathrm{~nm}$, which indicates the formation of $N$-carbethoxyhistidine (Wakayama et al., 1996). The absorption spectra of isoform 1 before and after DEP modification are shown in Fig. 2. The number of histidine residues which were modified by $0.325 \mathrm{mM}$ DEP were determined from the increase in the absorbance at $246 \mathrm{~nm}$, using an extinction coefficient of $3,200 \mathrm{M}^{-1} \mathrm{~cm}^{-1}$. The result shows that 8.5 histidine residues per mole of isoform 1 were modified by $0.325 \mathrm{mM}$ DEP when the enzyme was incubated with DEP only. The number of modified histidine residues decreased to 6.5 in the presence of methyl- $\beta-C D$ as a protective substrate. Hence, methyl- $\beta-\mathrm{CD}$ could protect two histidine residues per mole of isoform 1 from the modification by DEP.

Digestion of isoform 1 and separation of peptides To localize the essential histidines, three forms of isoform 1 (native, DEP-modified, and methyl- $\beta-\mathrm{CD}$ protected prior to the modification) were digested by trypsin. The HPLC profiles of the peptides are shown in Figs. 3 and 4. The peptides detection was performed at $210 \mathrm{~nm}$ (Fig. 3), while the detection of the modified-histidine product was followed at $246 \mathrm{~nm}$ (Fig. 4). When these profiles were compared, it was found that the peaks eluting at $R_{\mathrm{t}} 11.34$ and $40.93 \mathrm{~min}$ (Fig. $3 \mathrm{~B}$ ) appeared when isoform 1 was modified with DEP, while the peaks at $R_{\mathrm{t}} 8.69$ and $15.48 \mathrm{~min}$ (Fig. 3A) disappeared. A comparison of Figs. $3 \mathrm{C}$ with $3 \mathrm{~B}$ confirmed the importance of these peaks. The peak eluting at $R_{\mathrm{t}} 11.34$ min decreased. The one at $R_{t} 40.93 \mathrm{~min}$ disappeared when isoform 1 was protected with methyl- $\beta-C D$ prior to DEP-modified. However, the peaks at $R_{\mathrm{t}} 8.69$ and 15.48 min increased in Fig. 3C. The appearance and disappearance of these peaks were confirmed

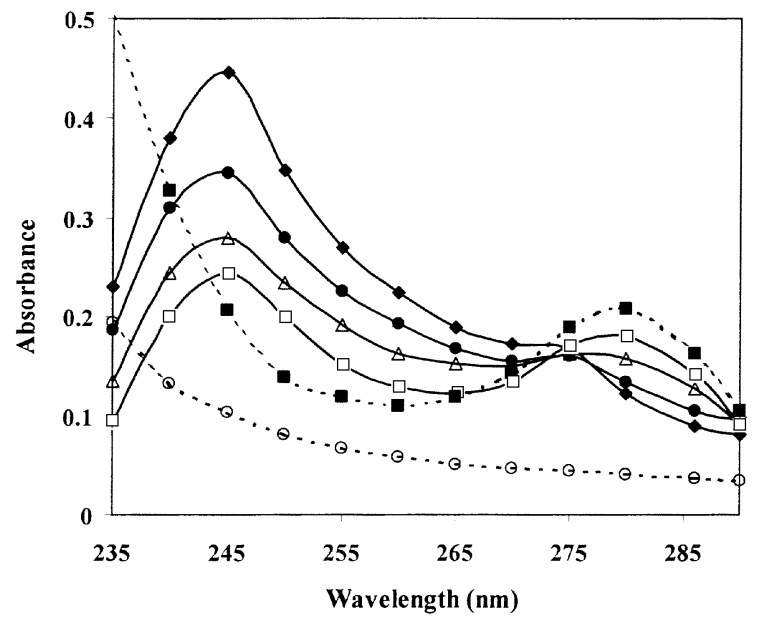

Fig. 2. Absorption spectra of CGTase isoform 1 before and after the modification with DEP. For control, CGTase isoform 1 $(100 \mu \mathrm{g} / \mathrm{ml}) \quad(\boldsymbol{\square})$ or DEP $0.65 \mathrm{mM} \quad(\bigcirc)$ were separately scanned. After a modification of $0-30 \mathrm{~min}(0 \mathrm{~min} \square, 10 \mathrm{~min} \triangle$, $20 \mathrm{~min}$, and $30 \mathrm{~min} \bullet$ ), the modified CGTase isoform 1 from each incubation time was scanned at the same wavelength range.

at $246 \mathrm{~nm}$ (Fig. 4) which was a specific wavelength to follow the modification with DEP. The profile comparison showed that the peaks eluting at $R_{\mathrm{t}} 11.34$ and $40.93 \mathrm{~min}$ (Fig. 4B) appeared when isoform 1 was modified with DEP, while these peaks were not seen in Fig. 4A. When comparing Fig. 4C with $4 \mathrm{~B}$, the peaks that eluted at $R_{\mathrm{t}} 11.34$ and $40.93 \mathrm{~min}$ decreased when isoform 1 was protected with methyl- $\beta-C D$ prior to DEP-modified. From these results, the peptides from the peaks at $R_{\mathrm{t}} 11.34$ and $40.93 \mathrm{~min}$ (Fig. 3B) should contain essential histidines since they were confirmed by absorbance at $246 \mathrm{~nm}$. These peaks were then pooled and submitted to mass determination and $\mathrm{N}$-terminal sequence determination for further characterization.

Mass analysis of peptides The peaks eluting at $R_{\mathrm{t}} 11.34$ and $40.93 \mathrm{~min}$ were dissolved in a solution of acetonitrile : $0.02 \%$ formic acid $(50: 50)$, then injected into mass spectrometer and their mass spectra were obtained. The peaks at $R_{\mathrm{t}} 11.34$ and 40.93 min were calculated to have molecular masses of 5,732 and 2,540 Da, respectively. 

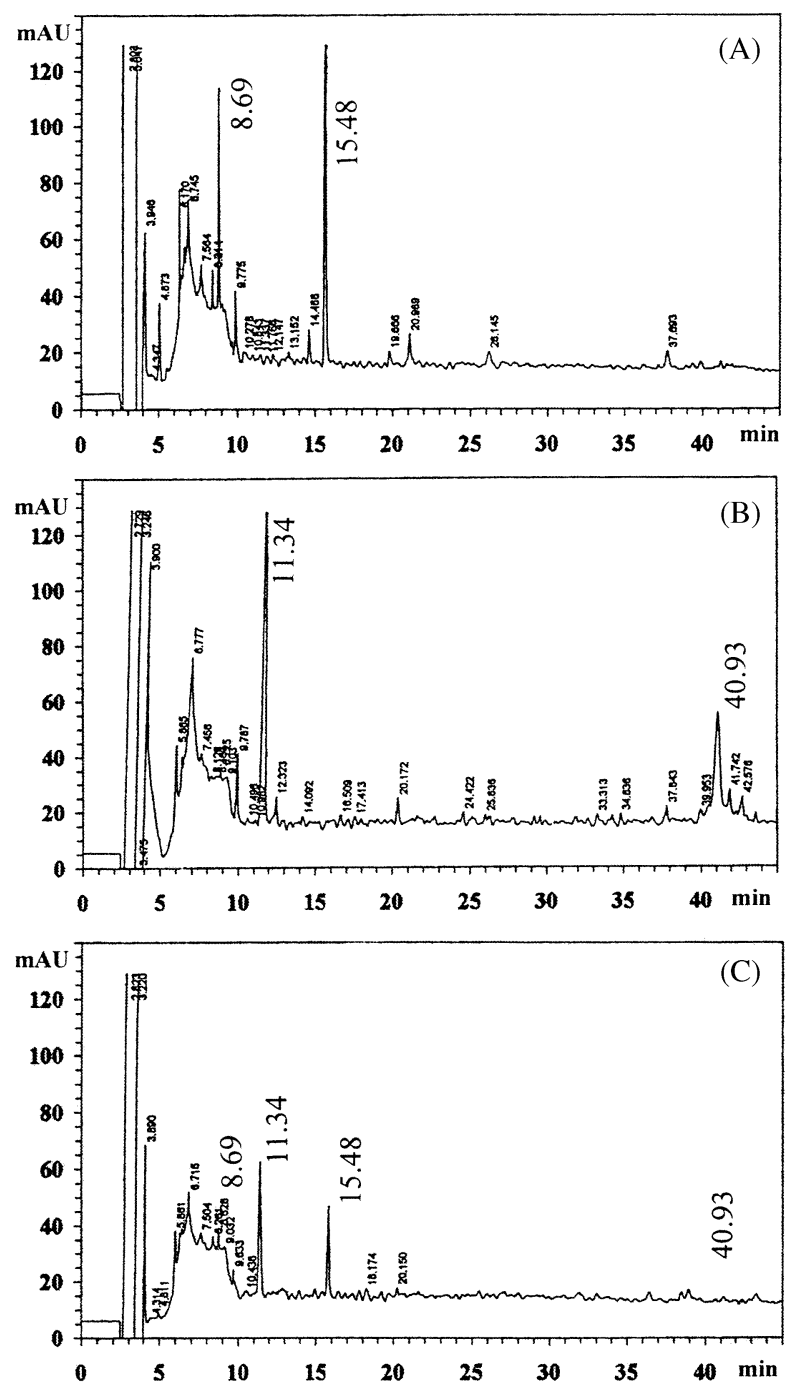

Fig. 3. HPLC chromatograms at $210 \mathrm{~nm}$ of the tryptic peptides of CGTase isoform 1. Digested products of (A) native isoform 1, (B) DEP-modified isoform 1, and (C) isoform 1 protected by methyl- $\beta-C D$ prior to DEP-modification.

Determination of $\mathbf{N}$-terminal sequence of peptides The amino acid sequence of the N-terminus of the two peptides of interest, the $R_{\mathrm{t}} 11.34$ and 40.93 min peaks, were determined by automated Edman degradation using the peptide sequencer. For the peak eluting at $R_{\mathrm{t}} 11.34 \mathrm{~min}$, the sequence F A Q K was identified. Also, the determined sequence for the peak eluting at 40.93 min was V I I D F A P N *H T.

Localization of essential histidines The position of essential histidine within the 40.93 min peptide peak was localized at His-140 when the overall information, including the size from mass spectra, the N-terminal sequence of the two peptides, and the action of trypsin (which is known to cleave the C-terminal of lysine and Arginine) was analyzed. Figure 5 shows the positions of the tryptic cleavage to generate peptide of an approximate size of 25 amino acids.
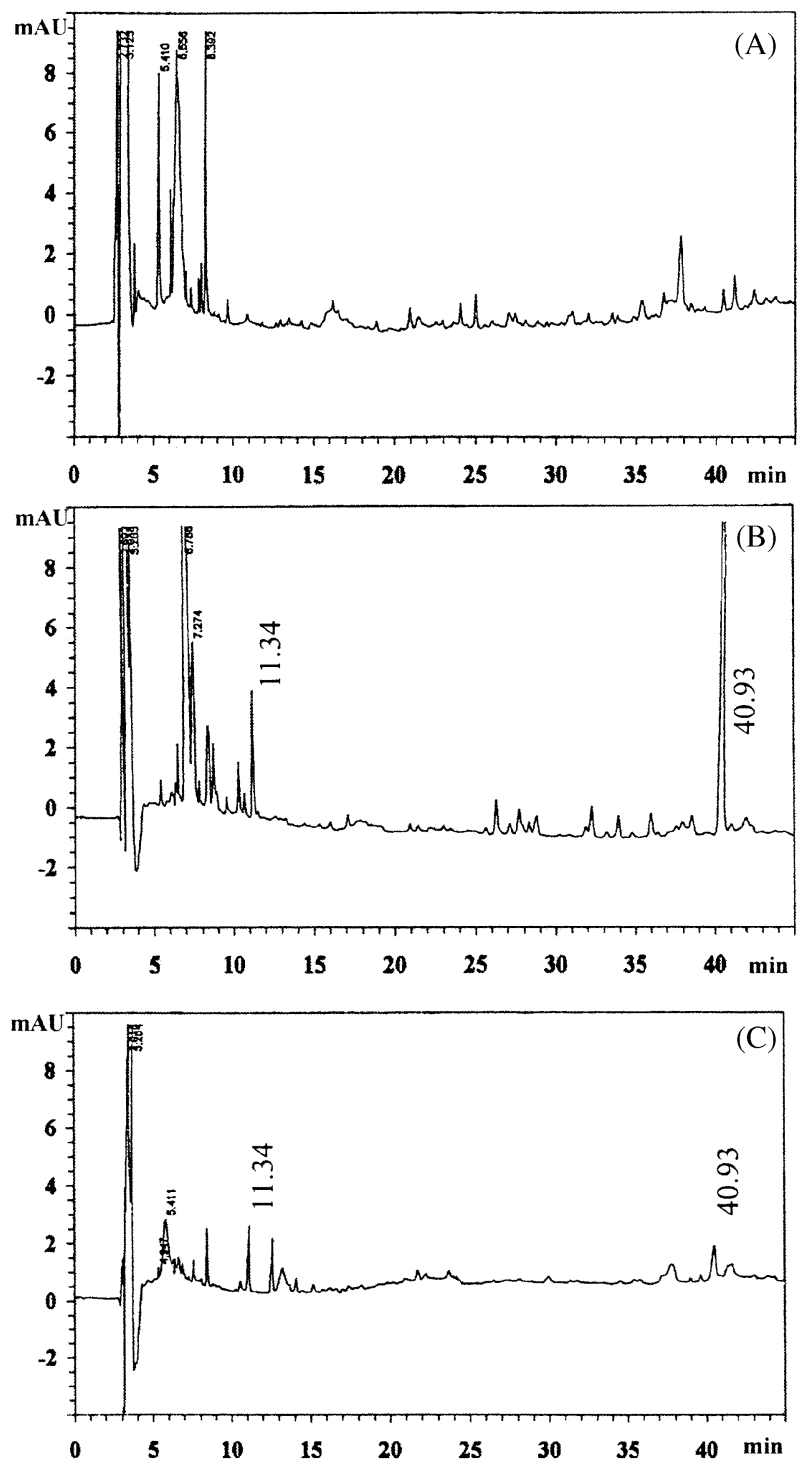

Fig. 4. HPLC chromatograms at $246 \mathrm{~nm}$ of the tryptic peptides of CGTase isoform 1. Digested products of (A) native isoform 1, (B) DEP-modified isoform 1 , and (C) isoform 1 protected by methyl- $\beta-C D$ prior to DEP-modification.

Trypsin cleaved at the C-terminal of Lys-131 and Arg-156. In this peptide, histidine (His-140) was at position 9 from the $\mathrm{N}$ terminus. For the peptide peak at $R_{\mathrm{t}} 11.34 \mathrm{~min}$ with the $\mathrm{N}$ terminal sequence $\mathrm{F} \mathrm{A} \mathrm{Q} \mathrm{K}$, the positions of the tryptic cleavage were at the C-terminal of Arg-284 and Arg-331 (Fig. 5). This peptide contained exactly 47 residues, equal to the number that was estimated from the mass determination. One histidine (His-327) was found at position 43 from the Nterminus.

\section{Discussion}

CGTase isoform 1 activity from Paenibacillus sp. A11 was 


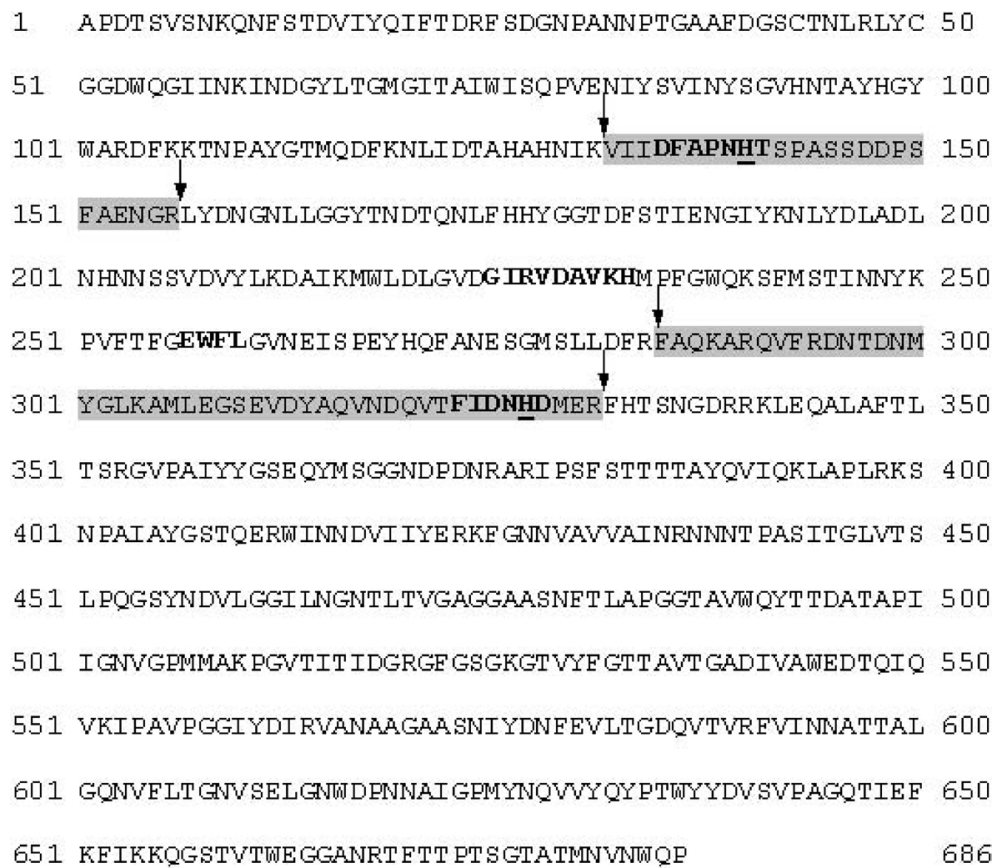

Fig. 5. Localization of essential histidines in CGTase from Paenibacillus sp. A11. Shaded areas are peptides with essential histidines (Val 132-Arg 156 is the $R_{t} 40.93$ min peptide and Phe 285-Arg 331 is the $R_{t} 11.34$ min peptide). The arrows indicate possible tryptic cleavage sites. The underlined $\mathrm{H}$ are the essential histidines that were identified. The bold letters indicate the conserved sequences by comparing them with other CGTases. The amino acid sequence (without signal peptide) was obtained from the deduced sequence of CGTase of this strain that was reported by Rimphanitchayakit, 2000.

completely inactivated by $1 \mathrm{mM}$ DEP. The activity could be protected when the $25 \mathrm{mM}$ methyl- $\beta-\mathrm{CD}$ substrate was added prior to the modification. This result suggests the involvement of histidine at the enzyme active site. Inactivation kinetics was followed by the plot of the logarithm of remaining activity versus time at different reagent concentrations. It was found that the activity decreased with increasing time and DEP concentration, indicating the pseudo first-order kinetics of inactivation. The plot of $k_{\text {inactivation }}$ versus DEP concentration gave a straight line, which suggests that the chemical modification was the result of a simple bimolecular reaction. The slope value of 0.84 from the double logarithmic plot of $k_{\text {inactivation }}$ versus DEP concentration indicates the inactivation results from the reaction of approximately $1 \mathrm{~mol}$ of DEP with 1 mol of enzyme (Levy et al., 1963).

From the comparison of the HPLC profiles of the tryptic digests of the native isoform 1 , DEP-modified, and methyl- $\beta$ $\mathrm{CD}$ protected from prior to the DEP-modification [as monitored by absorbance at $210 \mathrm{~nm}$ for peptides and $246 \mathrm{~nm}$ for modified-histidine ( $\mathrm{N}$-carbethoxyhistidine)], the peaks at $R_{\mathrm{t}} 11.34$ and 40.93 min were selected for analysis since they showed a significant difference in the peak height among Figures 3A, B, and C. This difference was also confirmed in Figures $4 \mathrm{~A}, \mathrm{~B}$, and C. It may be proposed that the peaks at $R_{\mathrm{t}}$ 8.69 and $15.48 \mathrm{~min}$ in the native isoform 1 (Fig. 3A), which disappeared upon DEP-modification (Fig. 3B), became the peaks at $R_{\mathrm{t}} 11.34$ and $40.93 \mathrm{~min}$. This proposal is possible since DEP-modification led to an increase in the hydrophobicity of the peptide (Means and Feency, 1971); the peaks at $R_{\mathrm{t}} 11.34$ and 40.93 min are less polar than the peaks at $R_{\mathrm{t}} 8.69$ and $15.48 \mathrm{~min}$, respectively.

The molecular mass that was determined by mass spectrometry of the peptide peaks eluting at $R_{\mathrm{t}} 11.34$ and $40.93 \mathrm{~min}$ were 5,732 and 2,540 daltons, respectively. The number of amino acids in the two peptides were then estimated to be about 47 and 25 residues, using the assumption that the average molecular mass of amino acids was in the range of 100-120 daltons (Voet and Voet, 1990). When the N-terminus sequences of both peptides were determined, the sequence F A Q K and V I I D F A P N H T were obtained. These data, in combination with the proposed tryptic cleavage sites, were then fitted into the deduced amino acid sequence of CGTase that was reported by Rimphanitchayakit (2000) (Fig. 5). Two histidines, His-140 and His-327, were then identified as essential residues of the CGTase isoform 1 from Paenibacillus sp. A11.

CGTase sequences that were previously reported, demonstrated four conserved regions, which were designated as regions A, B, B', and C, respectively (Wind et al., 1995). Three conserved regions contained histidine residues (Fig. 5). It should be noted that a similar pattern of conserved histidine residues was demonstrated in $K$. pneumoniae and some species of Bacillus. From the three-dimensional structure of $B$. stearothermophilus CGTase, His-140 and His-327 bound the 
same glucose unit of amylose; whereas His-233 bound a different one (Kubota et al., 1991). Nakamura (1993) reported that the three histidine residues (His-140, His-233, and His327) of CGTase from alkalophilic Bacillus sp. 1011 were essential histidine residues in the active center of the enzyme. His-327 was important for catalysis over an alkaline $\mathrm{pH}$ range, because a decrease in activity was observed when the replacement of His-327 by the asparagine residue was performed. For His-140 and His-233, different roles in catalysis could not be clarified. In this study, only two essential histidines, His-140 and His-327, were identified in the active site of the CGTase isoform 1 from Paenibacillus sp. A11. The result from an analysis of the peptides confirmed the data that was produced by spectra analysis and calculation of the active site histidines, which also suggested two histidine residues. His-233 was not identified, which means it may not be at the active site of isoform 1 , or the techniques of chemical modification and substrate protection could not identify this residue. Another alternative is that the peptide that contains this residue may be one of the small peaks (Fig. 3A), due to the inconsistency of the trypsin digestion at the cleavage site which gave rise to the peptide. When the peptide peak was small, it was impossible to see the differences of the peak among the native, modified, and protected forms of the enzyme. To prove the importance of His-233, the use of other hydrolytic enzymes with different cleavage sites may be tried. The technique of the site-directed mutagenesis may also be used for further identification.

Acknowledgments We would like to thank Dr. Prasat Kittakoop of the National Science and Technology Development Agency for his help in the mass spectrometric determination and data analysis. Special thanks also to Prof. Kenji Aoki of Kobe University, Japan for the N-terminal sequencing of peptides. This work was supported in part by research grants from the Graduate School of Chulalongkorn University (2000).

\section{References}

Bart, A. (2000) The three transglycosylation reactions catalyzed by cyclodextrin glycosyltransferase from Bacillus circulans (strain 251) proceed via different kinetic mechanisms. Eur. $J$. Biochem. 267, 658-665.

Bender, H. (1986) Production, characterization and application of cyclodextrins. Adv. Biotech. Proc. 6, 31-71.

Bradford, M. M. (1976) A rapid and sensitive method for the qualitatively of microgram quantities of protein utilizing the principle of protein-dye binding. Anal. Biochem. 72, 248-254.

Delforge, D., Devreese, B., Dieu, H., Delaive, E., Beeumen, J. and Remacle, J. (1997) Identification of lysine 74 in the pyruvate binding site of alanine dehydrogenase from Bacillus subtilis. $J$. Biol. Chem. 272, 2276-2284.

Fuwa, H. (1954) A new method for microdetermination of amylase activity by the use of amylases as the substrate. $J$. Biochem. 41, 583-603.
Kaskangam, K. (1998) Isolation and characterization of cyclodextrin glycosyltransferase isozymes from Bacillus sp. A11. Masters Thesis, Faculty of Science, Chulalongkorn University.

Kato, T. and Horikoshi, K. (1984) Immobilized cyclomaltodextrin glucanotransferase of an alkalophilic Bacillus sp. No. 38-2. Biotechnol. Bioeng. 26, 595-598.

Kitahata, S., Tsuyama, N. and Okada, S. (1974) Purification and some properties of the cyclodextrin glycosyltransferase from a strain of Bacillus species. Agric. Biol. Chem. 38, 387-393.

Kitahata, S. and Okada, S. (1982a) Purification and properties of cyclodextrin glycosyltransferase from Bacillus stearothermophilus TC-60. Denpun Kagaku. 29, 7-12.

Kitahata, S. and Okada, S. (1982b) Comparison of action of cyclodextrin glycosyltransferase from Bacillus megaterium, Bacillus circulans, Bacillus stearothermophilus and Bacillus macerans. Denpun Kagaku. 29, 8-13.

Kobayashi, S., Kainuma, K. and Suzuki, S. (1978) Purification and some properties of Bacillus macerans cycloamylose (cyclodextrin) glucanotransferase. Carbohydr. Res. 61, 229-238.

Kubota, M., Matsuura, Y., Sakai, S. and Katsube, Y. (1991) Structure of cyclodextrin glycosyltransferase complex with $\beta$ cyclodextrin. Denpun Kagaku. 38, 141-146.

Lee, Y. S. and Cho, Y. D. (2001) Comparison of biochemical and immunological properties between rat and nicotiana glutinosa ornithine Decarboxylase. J. Biochem. Mol. Biol. 34, 408-414.

Levy, H. M., Leber, P. D. and Ryan, E. M. (1963) Inactivation of myosin by 2,4-dinitrophenol and protection by adenosine triphosphatase and other phosphate compounds. J. Biol. Chem. 238, 3654-3659.

Mattson, P., Meklin, S. and Korpela, T. (1990) Analysis of cyclomaltodextrin glucanotransferase isozymes by isoelectric focusing in immobilized $\mathrm{pH}$ gradients. J. Biochem. Biophys. Methods 20, 237-246.

Means, G. E. and Feeney, R. E. (1971) Chemical modification of proteins. Holden-Day Inc., San Francisco, USA.

Nakamura, A., Haga, K. and Yamane, K. (1993) Three histidine residues in the active center of cyclodextrin glucanotransferase from alkalophilic Bacillus sp. 1011: Effects of the replacement on $\mathrm{pH}$ dependence and transitionstate stabilization. Biochemistry 32, 6624-6631.

Nakamura, N. and Horikoshi, K. (1976) Characterization and some cultural conditions of a CGTase-producing alkaophilic Bacillus sp. Agric. Biol. Chem. 40, 753-757.

Pongsawasdi, P. and Yagisawa, M. (1987) Screening and identification of a cyclomaltodextrin glucanotransferase producing bacteria, J. Ferment. Technol. 65, 463-467.

Rimphanitchayakit, V., Tonozuka, T. and Sakano, Y. (2000) DNA cloning of cyclodextrin glucanotransferase gene from Bacillus circulans A11; in Proceedings of The $1^{\text {st }}$ Conference on Science \& Technology University-Industry Linkages Under TJTTP, Soontaros, S., Rimphanitchayakit, V., Pungrassamee, P. and Hansuebsai, A. (eds.), pp. 175-181, Aksornsobhon Co., Bangkok, Thailand.

Siuzdak, G. (1996) Mass spectrometry for Biotechnology. Academic Press Inc., San Diego, USA.

Tongsima, A. (1998) The active site of cyclodextrin glucanotransferase from Bacillus sp A11. Masters Thesis, Faculty of Science, Chulalongkorn University.

Voet, D. and Voet, J. G. (1990) Biochemistry. John Wiley \& Sons, 
New York, USA.

Wakayama, M., Tsutsumi, T., Yada, H., Sakai, K. and Morigushi, M. (1996) Chemical modification of histidine residues of $\mathrm{N}$ acyl-D-glutamate amidohydrolase from Pseudomonas sp. 5f-1. Biosci. Biotech. Biochem. 60, 650-653.

Wind, R., Liebl, W., Buitlaar, R., Penninga, D., Spreinat, A., Dijkhuizen, L. and Bahl, H. (1995) Cyclodextrin formation by thermostable $\alpha$-amylase of Thermoanaerobacterium thermosulfurigenes EM1 and reclassification of the enzyme as a cyclodextrin glycosyltransferase. Appl. Environ. Microbiol. 61, 1257-1265.

Yagi, Y., Sato, M. and Ishikura, T. (1986) Comparative studies of CGTase from Bacillus sp. and Micrococcus sp. and production of cyclodextrins using those CGTase. J. Jpn. Soc. Starch Sci. 2, 144-151. 